\title{
POVOS INDÍGENAS EM TEMPO DE PANDEMIA
}

\author{
INDIGENOUS PEOPLES IN PANDEMIC TIMES
}

\begin{abstract}
Leonardo Rangel ${ }^{1}$
Selma Capinan ${ }^{2}$

\section{RESUMO}

O presente artigo discorre sobre uma intervenção extensionista originada pelo edital Rede de Prevenção à Covid19, do Doutorado Multi-institucional e Multidisciplinar em Difusão do Conhecimento-DMMDC-da UFBA em junho de 2020, cujo objetivo foi capacitar professores, agentes de saúde e lideranças nos cursos de a) cuidados com a saúde indígena e o de audiovisual, os quais ocorreram simultaneamente, cuja metodologia entrelaçava-os pelos eixos temáticos. Foram parceiros da Universidade Federal da Bahia (UFBA) e do Museu Nacional de Cultura Afro-Brasileira (MUNCAB), a Associação de Mulheres Pankararu, o Instituto Federal da Bahia- IFBA- e um grupo de professores voluntários. Foram 15 alunos inscritos da etnia Pankararu, mas foram 10 o número de concluintes, com a produção de 9 vídeos que compuseram a campanha profilática á Covid. A metodologia utilizada foi o que podemos chamar de "conexões em conversa", compreendidos como encontros mediadores e/ou experiências modificadoras. O resultado da intervenção foi a formação do Coletivo audiovisual Y-MBU-U, produtor do Museu Virtual do Povo Pankararu, além de ampliar o uso das tecnologias digitais para os professores e contribuir para a aquisição de equipamentos para o posto de saúde e ampliar as discussões sobre os direitos à saúde indígena.
\end{abstract}

Palavras-chaves: Povos indígenas; Pandemia; Etnoaudivisual; Pankararu.

\begin{abstract}
This article describes a university extension intervention created in response to a Request for Proposals (RFA) by the COVID-10 Prevention Network of the Multi-Institutional and Multidisciplinary Doctorate in Knowledge Diffusion-DMMDC-of Federal University of Bahia (UFBA). The project was implemented in June 2020 to train teachers, health agents, and leaders using courses on indigenous health care and audiovisual techniques, simultaneously, intertwining these courses based on thematic axes. The project implementation was based on a partnership of UFBA and the National Museum of Afro-Brazilian Culture (MUNCAB) together with the Pankararu Women's Association and the Federal Institute of Bahia - IFBA-and also a group of volunteer teachers. Fifteen Pankararu students enrolled in the course, but ten concluded it. The methodology used was what we could call "connexions in conversation," understood as mediating meetings and/or modifying experiences. As a result of this intervention, the audiovisual collective Y-MBU-U was created, which produced the Virtual Museum of the Pankararu People. It also amplified the teachers' use of digital technologies, the discussions on indigenous people's right to health, and contributed to equipment acquisition for the health clinic.
\end{abstract}

Keywords: Indigenous people; Pandemic; Ethno-audiovisual; Pankararu.

\footnotetext{
${ }^{1}$ Atualmente é Professor de Sociologia do Instituto Federal de Educação, Ciência e Tecnologia- IFBA. Doutor e Mestre em Educação pela Universidade Federal da Bahia. e-mail: leonardorangelrreis@gmail.com

${ }^{2}$ Atualmente é Doutoranda em Educação pela UAA-Universidade Autônoma do Paraguai. Mestra em Urbanismo e Arquitetura (UFBA). e-mail: selmacapinan@gmail.com
} 


\section{Revista \\ Debates Insubmissos}

\section{INTRODUÇÃO}

O presente artigo perpassa alguns gêneros ao incorporar uma narrativa que mais se aproxima de um ensaio livre, etnográfico ou de um relatório de uma prática extensionista que envolveu uma experiência de viagem de campo, mediada pelo ciberespaço. Para iniciarmos essa trajetória, traçaremos o cenário, o percurso e os resultados do Projeto "Povos Indígenas em Tempo de Pandemia", cujo objetivo foi instrumentalizar a etnia Pankararu a produzir campanhas educativas com sentido profilático, mediante a aquisição das habilidades desenvolvidas nos cursos: 1) Cuidados com a Saúde em Tempo de Pandemia e 2) Roteiro e Produção Audiovisual Educativo, na modalidade de extensão, cuja metodologia configurou-se pela inter e transdisciplinaridade, perpassado por temas transversais, na modalidade EaD.

Ao iniciarmos o projeto, o panorama era bastante sombrio e assustador, levando-nos a lançar a seguinte questão: sob quais olhares se configuravam as vidas e a preservação dos territórios dos povos indígenas? Assim, começamos a desvelar o cenário no qual iríamos atuar, em junho do corrente ano.

Inquietações pairavam sobre os mais diversos olhares, incluindo os mediados pela imprensa internacional e local, assim como as redes sociais, ambas se voltavam, enfaticamente, para os aspectos de vulnerabilidade dos povos indígenas brasileiros. Anterior à pandemia, este contexto de vulnerabilidade e abandono já estava perceptível ao mundo, frente à fragilidade de todo o ecossistema da Amazônia e de todos os povos decorrente destes territórios, ganhando notoriedade pelo ato de denúncia do líder Yanomami David Kopenawa à Organização das Nações Unidas (ONU) por meio do Instituto Socioambiental (ISA), sobre o desmonte ambiental, em fevereiro, do corrente ano.

Afigurando-se, portanto, a fotografia do descaso registrada a cada dia, com episódios de uma série inacabada, em capítulos, a despeito da resposta agressiva dada ao renomado Fotógrafo Sebastião Salgado, pela FUNAI, com a devolução da doação realizada no valor aproximado de 1 milhão de reais. A tratativa deu-se em razão do apoio ao lançamento da campanha que mobilizou autoridades mundiais e artistas renomados, como Madonna, Paul MacCartney, Chico Buarque, dentre outros, em prol dos povos indígenas da Amazônia. Além 


\section{Revista \\ Debates Insubmissos}

desses desdobramentos desrespeitosos, foram também encenados envios de colchões velhos e infectados para população da Terra Indígena Xapecó, em Ipuaçu, Vale do Itajaí, Santa Catarina - de acordo com a publicação, datada em 14 de agosto de 2020, pelo G1.

A drasticidade das ações governamentais se amplia com o Projeto de lei n $^{\circ}$ 192/2020, o qual permite garimpos em terras indígenas, gerando o aviltamento de direitos garantidos constitucionalmente e reitera o que, historicamente, constatou-se nesses mais de 500 anos alavancados, principalmente, pelos constantes conflitos de terras que os colocaram em estado de alerta sobre a integridade física.

Não obstante, as vozes genocidas - tenho certeza - atualizam-se e ecoam na fala do ministro do Meio Ambiente, Ricardo Salles, registradas em vídeo da delação feita pelo exministro Mouro, em que dizia: "ser o momento propício para deixar passar a boiada", contexto condescendente com a entrada do agronegócio ou de mineradoras em terras indígenas. Panorama de violência, a exemplo das inculpadas, pela Comissão Pastoral da Terra (CPT), em 2019, sobre as 27 mortes de lideranças indígenas. Segundo a Comissão, todas elas estavam relacionadas às "violências institucionalizadas", em conflitos de terras.

O processo opressivo, as narrativas e os discursos da colonização trajam-se de neoliberalismo pós-moderno. Os colonizadores se denominam, na atualidade, de Estado Democrático de Direito, segundo o autor quilombola:

Queimam, mas também inundam, implodem, trituram, soterram, reviram com suas máquinas de terraplanagem tudo aquilo que é fundamental para a existência das nossas comunidades, ou seja, os nossos territórios e todos os símbolos e significados dos nossos modos de vida (BISPO, 2018, p. 58).

Vale ressaltar que os problemas indígenas dizem respeito às suas mais diversas etnias, das regiões do Brasil. Especificamente, por tratarmos do Povo Pankararu, indígenas, moradores do Nordeste brasileiro, do sertão pernambucano, o contato constante com a sociedade ocidental desde o período colonial, levou-os à perda do próprio idioma. No século XX, ocasionado pelo impacto causado com a construção da barragem do Rio São Francisco, a população é deslocada da área ribeirinha para outras áreas que sofrem com a escassez hídrica, sem que isto implicasse 


\section{Revista \\ Debates Insubmissos}

em ações compensatórias. Tais aspectos somam-se a outro agravante, que é o déficit alimentar em algumas das aldeias, aumentando os fatores de risco para a pandemia da Covid-19.

Ao iniciarmos o projeto, em junho de 2020, o panorama da Covid-19 em relação ao número de indígenas infectados era de mais de cinco mil na região amazônica, com 293 mortes (APIB, junho 2020, p. 3), totalizando em todo Brasil 9166 infectados, com 378 mortes, dados demonstrativos da situação crítica. Naquele momento, a maior incidência de infectados era entre os povos Kokama (AM), Guajajara (MA), Tikuna (AM) e Kayapo (PA).

Tais números refletem a qualidade das políticas de saúde específicas para os povos indígenas. No universo da população brasileira, em que os povos indígenas representam $0,4 \%$ do total da população, somam-se por volta de 900 mil indígenas (IBGE, 2010), cuja concentração é de 37,4\% na Amazônia, comportando o maior contingente, a segunda região com 25,5\%, concentrados na região Nordeste. Os fatos, assim como os dados alarmantes, se contrapõem à política da FUNAI, que de acordo com dados do mesmo relatório, apontam que de abril a junho de 2020, ou seja, em plena crise da primeira onda da pandemia, o órgão havia gasto $1,18 \%$ do seu orçamento com a saúde indígena.

Por estarmos no Nordeste, próximos dessa realidade e observando o panorama descrito, decidimos promover uma intervenção social por meio do Projeto "Povos Indígenas em Tempo de Pandemia", contemplado pelo edital do DMMDC- Rede para o Enfrentamento da Covid-19, junto ao Povo Pankararu, que está situado nas regiões das fronteiras entre Paulo Afonso (BA), Tacaratu (PE), Petrolândia (PE), Jatobá (PE) e Alagoas. São eles a segunda maior população indígena do Nordeste, representando $39 \%$ da população dentre as diversas etnias, com o contingente populacional de aproximadamente 8447 mil habitantes, dos quais, cerca de 1500 localizam-se entre Salvador e São Paulo. É com este povo que venho desenvolvendo pesquisa, motivada pela nossa ligação afetiva e ancestral. 


\section{VOLTANDO UM POUCO NO TEMPO, QUANDO SE CELEBRAVA: UM RELATO DE EXPERIÊNCIA}

Em 12 de março de 2020, com o estabelecimento das barreiras sanitárias, foi também a data da minha saída da Aldeia. O clima era de tranquilidade, pairando um sentimento de gratidão pelas entregas das oferendas e compromissos religiosos, fechando o ciclo das tradições: Corrida do Umbu, o Menino do Rancho e das Penitências ${ }^{3}$. Emoções que podem ser traduzidas pela filosofia Guarani do Ñande Reko, que emerge da cosmovisão da ideia de irmandade, estendida para além das relações humanas, para todos os seres viventes, não humanos, que compartilham de uma mesma origem e se acolhem mutuamente sem estabelecer distinções hierarquizantes e retificadoras.

Assim, também para os povos Zapatistas, a palavra "bats 'i” dar um sentido unívoco a duas palavras, tanto significa "originário" quanto "verdadeiro", cuja acepção relaciona-se com a vida dos povos, (bats'i ants vinik), considerando, portanto, o vínculo daqueles que pertencem a um lugar, que crescem e se relacionam ali, quer dizer, daqueles que não apenas possuem uma terra, mas pertencem a ela (MOREL, 2019).

Aludir à centralidade da terra, tanto para os povos originários Zapatistas quanto para os povos pindoramas se dá pela acepção da palavra que, para além do conceito geográfico e do conceito de chão, representa uma divindade e ganha sentido com a palavra $(C y)$ em Tupy Guarany, que se manifesta nas deusas Nandecy e Cooaracy. De forma similar, na língua zapatista (yuval lum), ela é, ao mesmo tempo, princípio vital do que existe (balumil), que é a condição indispensável e inseparável da existência dos povos. Terra como mãe, território com identidades. E, naqueles dias que antecedem o sinal de alerta da pandemia da Covid-19, pisar

\footnotetext{
${ }^{3}$ Ciclo de festas que se iniciam em novembro e terminam em fevereiro. Inicia com a corrida do Umbu, ou imbu que é uma fruta sagrada, passa para o Menino do Rancho-Ritual de iniciação para crianças e jovens, com madrinhas e pagamento de promessas com almoço comunitário, e Penitência, ritual em que se dança o toré com galhos de cansanção no ombro.
} 


\section{Revista \\ Debates Insubmissos}

compassadamente nas rodas do Toré significava ser parte dançante da terra, para celebrar o encanto da lua, da terra e da existência.

O clima de festa, rapidamente, iria transformar drasticamente os convívios e as práticas coletivas. Passando do comportamento de compartilhamento, festejos e confraternizações, em rumores. Um clima de suspeição, logo se instalou. Eu inclusive fui mencionada no WhatsApp comunitário como suspeita de transmitir a Covid-19, assim também o padre que havia retornado da Europa, o auxiliar de enfermagem, que se pronunciou publicamente pelo WhatsApp, como estando infectado, mas que não havia visitado os familiares naquele momento de festividade na Aldeia.

E, como o vento, os rumores por todos os lados, em todas as direções. Eram rumores e justificativas sociais constantes de não contaminação, outros de acometimento. No ar, além do vírus, espalharam-se medo e preconceito, no sentido de não saber lidar com a nova realidade. A tranquilidade cedeu espaço ao amedrontamento, simultaneamente, à inserção de uma nova forma de viver e de relacionar-se. A vida coletiva anuiu ao espaço do isolamento e, com ela, a resistência, ao uso de máscara, por alguns.

Os indígenas Pankararu estavam sobressaltados, pois rondava o espírito do medo. Configurando-se como uma sociedade movida pelo medo. Para os filósofos Bauman (2008), ou para Heidegger (1979), este sentimento é atribuído quando a impropriedade e a falta de sentido passam a serem os catalizadores, fazendo com que as circunstâncias nos arrastem de modo a criar estranhamento, tornando-nos alienados de nós mesmos. Os meios de comunicação apresentam previsões matemáticas que anunciam que chega à casa de 1 milhão, o número de óbitos causados pela pandemia em escala mundial.

Se o medo nos desapropria, por outro lado, a pandemia ora vivenciada no horizonte de nossa existência, acentua, também, a percepção do valor da própria existência e, para além, sobre os outros - crianças, adultos e velhos - o ambiente intensifica as relações, propiciando um convite para "sentirfazerpensar", momento em que pudemos, através dos vídeos produzidos, perceber os acordos e os vínculos com a ancestralidade porque "se as pessoas não tiverem vínculos profundos com sua memória ancestral, com as referências que dão sustentação 
a uma identidade, vão ficar loucas" (KRENAK, 2019, p. 14). Atenuando os indícios de que vivemos numa verdadeira crise civilizacional (LEFF, 2016; SERRES, 2009), ou num tempo das catástrofes (STENGERS, 2015).

A pandemia modelando formas de isolamento também no território Pankararu, encontrou na natureza uma aliada, com chuvas que fizeram o sertão esverdear-se e florescer, possibilitando que o "tronco velho"4 voltasse às práticas agrícolas, à relação com a terra, ao movimento de proteção à saúde mental e psicossocial. Processo que nos remete à obra de Tsing (2019), quando fala da relação da Paisagem, da sua forma entrelaçada com outras vidas e o que ela "aprendeu com seus 'professores excepcionais', os que foram seus interlocutores na pesquisa de campo, em Satoyama, no Japão, que revitalizaram sua compreensão de como a perturbação poderia iniciar uma história da vida da floresta".

\section{METODOLOGIA}

A intervenção realizada pelo projeto Povos Indígenas em Tempo de Pandemia capacitou professores, estudantes, lideranças e agentes de saúde comunitária. O total de 15 pessoas, originalmente previsto para 30, mas que impuseram dificuldades como: a falta de equipamento e de acesso à internet intermitente, agravada pela falta de articulação adequada para as inscrições pelas associações indígenas parceiras. Remodelamos a proposta para 15 alunos. $\mathrm{O}$ Curso previa 150 horas, entretanto finalizou com 200 horas.

Os cursos articulavam duas áreas do conhecimento que seguiam entrelaçadas e simultâneas, com currículo transversal, interdisciplinar com foco na educação intercultural, na modalidade EaD: (i) curso de cuidados com a saúde em tempo de pandemia; e, (ii) curso de roteiro e produção audiovisual educativos, como uma estratégia de difusão do conhecimento, comunicação e prevenção para os povos indígenas do sertão pernambucano (Pankararu). A proposta consistia em promover uma campanha educativa, através dos vídeos, fortalecendo a

\footnotetext{
${ }^{4}$ Tronco Velho significa as antigas gerações
} 
formação de novos comportamentos, assim como as novas relações de cuidados alimentares e de higiene para o enfrentamento, de maneira profilática, da contaminação da Covid-19.

As rodas de conversas (virtuais), antes da implementação do projeto, serviram para um diagnóstico participativo intercultural, buscando definir o desenho final do projeto. Sinalizando os temas das aulas abertas, assim como o de contemplar a participação ampliada da comunidade do projeto.

Da mesma forma, os conteúdos do próprio projeto foram advindos de tais questionamentos. Sendo os temas emergentes dos diálogos e dos desejos expressos pelo Povo Pankararu. Encontros que apontaram para a necessidade de uma orientação para os aspectos moventes dos sentidos e da emoção, dos transtornos de ansiedade e do estresse causado pela pandemia, com o objetivo de mapear comportamentos favoráveis e desfavoráveis capazes de potencializar a prevenção. Uma proposta de construção de conhecimento que encontra intersecção com o pressuposto da dinâmica das conversações trazida por Maturana (2005), que entende que a realidade se constitui nas conversações, ao dizer que: "Os seres humanos somos o que conversamos, e é assim que a cultura e a história se encarnam em nosso presente" (MATURANA, 2005, p. 91)

Povos Indígenas em Tempo de Pandemia teve início em 22 de junho de 2020, com a Live interativa de Antônio Bispo, autor quilombola, conversando sobre as conexões entre indígenas e quilombolas. Uma forma dialógica e interativa, o que poderíamos chamar de roda de conversa (FREIRE, 1996) ou sensibilização. Fala carregada da visão contra colonial, chamando a atenção para "outras pandemias", causadas pelo que ele denomina de mentalidade e práticas euro-cristã-monoteístas, materializadas na pulverização de agrotóxicos pelo agronegócio que tem levado à morte de peixes e de abelhas. Propiciando pandemias que atacam todos os seres. Reflexão finalizada pelo autor como de "provar do próprio veneno".

De maneira contundente, estabelece relações entre a Doença de Chagas e a relação do quantitativo das verbas destinadas à pesquisa e às soluções. Para o autor, a falta de prioridade acomete uma parte da população, mas, especificamente, os pobres agricultores. Estas análises alargaram o debate sobre a compreensão político-econômica da pandemia. Nas suas 


\section{Revista \\ Debates Insubmissos}

argumentações, mostra a distopia conceitual do termo desenvolver, ou desenvolvimento. Para ele, envolver-se com a natureza para quilombolas e indígenas, promove, então, o fortalecimento, contrário à ideia de desenvolvimento. O conceito aludido promove a desapropriação de sentidos, de multiplicidades das espécies, das frutas, reduzindo, assim, inclusive nas escolhas alimentícias, tornando-as inadequadas ao fortalecimento da imunidade das pessoas.

Essas rodas de conversas aos sábados, sempre às 16 horas, eram abertas, sendo transmitidas pelo Facebook, página especificamente criada para o projeto, com o mesmo título. Veículo pelo qual eram disseminadas as informações para todos os moradores de dentro e de fora das 17 aldeias. A perspectiva do projeto era de mobilizar as comunidades, contribuindo para uma educação emancipadora, que possibilitasse a autonomia desse povo. Pois toda agenda formativa, minimamente preocupada com o bem comum e com a sobrevivência das gerações futuras, necessita da criação de mecanismos de denúncia.

Tais trocas de experiências e de colaborações de diversas ordens puderam ser compreendidas como encontros mediadores e/ou experiências modificadoras e transformadoras do si, através dos outros (FOUCAULT, 1984), e a conversa surge como abertura às possibilidades de sermos afetados e de nos afetar pelos outros, sejam pessoas, como personagens conceituais (DELEUZE, 1992).

Buscamos, portanto, não realizar uma delimitação antropológica do outro. Ao invés disso, concebemos os outros como forças que nos afetam e nos formam em redes, com as quais pudemos interagir, de variados modos. Dito isto, na nossa segunda semana, a aula aberta aos sábados, foi com a escritora, ativista Indígena do Povo Kambeba, Márcia Kambeba, que falou sobre a educação indígena, a memória e a história, esclarecendo que as vivências comunitárias fazem parte da escola, mostrando o não-muro das escolas.

Nisso podemos também perceber outras plasticidades das práticas educativas. Fazendo compreender que em tempo de pandemia, nas escolas indígenas, existem outras formas de enfrentar e de compreender tal realidade, mostrando-nos sobre a importância de movimentar e mobilizar as conversas no seio da própria família, de modo a experimentá-las nas suas várias 


\section{Revista \\ Debates Insubmissos}

práticas. A conversa como uma das possibilidades do encontro - potente tecnologia de transformação do eu (FOUCAULT, 1984) e suas reverberações.

Todo o processo de construção pedagógica do projeto protagonizou as "conexões em conversa", as quais não visam criar imagens estáveis de nós mesmos, nem dos outros, nem visam produzir textos e/ou outros produtos a partir de padrões rígidos ou de modelos inflexíveis a serem seguidos, porque aceita o movimento do devir como maior que qualquer pretensão de estabilização. Desse modo, propõe outras possibilidades de compreensão dos "cotidianos praticados, não mais reduzidos a lugares da mesmidade/repetição" (FERRAÇO; ALVES, 2018, p. 46). Tomando a teórica como práxis, precisávamos abrir a discussão para ouvirmos a comunidade e também trocar experiências, buscando construir um currículo com múltiplos aspectos de interesse de toda comunidade. A exemplo de trazer a tradição como tecnologia pedagógica.

A metodologia utilizada dialogou com as epistemologias das ciências, com as tecnologias e mídias sociais e os saberes ancestrais, em aliança com a ecologia humana dos 'fazeressaberes', 5 traduzindo-se no âmbito da formação de educadores/as como potencializadora de oportunidade para a implementação de uma pedagogia contrahegemônica, instaurando novos acordos emancipatórios. Inspirado nas experiências suleadoras, cujo desenho da América invertida está referendado pelo artista uruguaio Joaquín Torres-García, sob o lema "Nosso Norte é o Sul” (Figura 1), o que se traduz como uma inversão, na qual as histórias de vida e do cotidiano têm valor de ciência, demarcando espaços de trocas e entrelaçamentos de saberes, ressignificando conhecimentos, assim como dos afetos.

Ao se inverter o mapa, fez-se urgente aprofundar aspectos existenciais e filosóficos, oportunizando também a discussão necropolítica deliberada que decreta formalmente que as pessoas podem ser mortas a partir de "mecanismos técnicos para conduzir a eliminação dos inimigos do Estado" (MBEMBE, 2018, p 83).

\footnotetext{
5 Estética da escrita que aprendemos com Nilda Alves (2002) na tentativa de, ao unirmos determinadas palavras, ampliar seus significados, inventando outros tantos, buscando romper com as marcas que carregamos da ciência moderna, sobretudo a maneira dicotomizada de analisar a realidade.
} 
Figura 1 - América invertida (1943) - Joaquim Torres-García

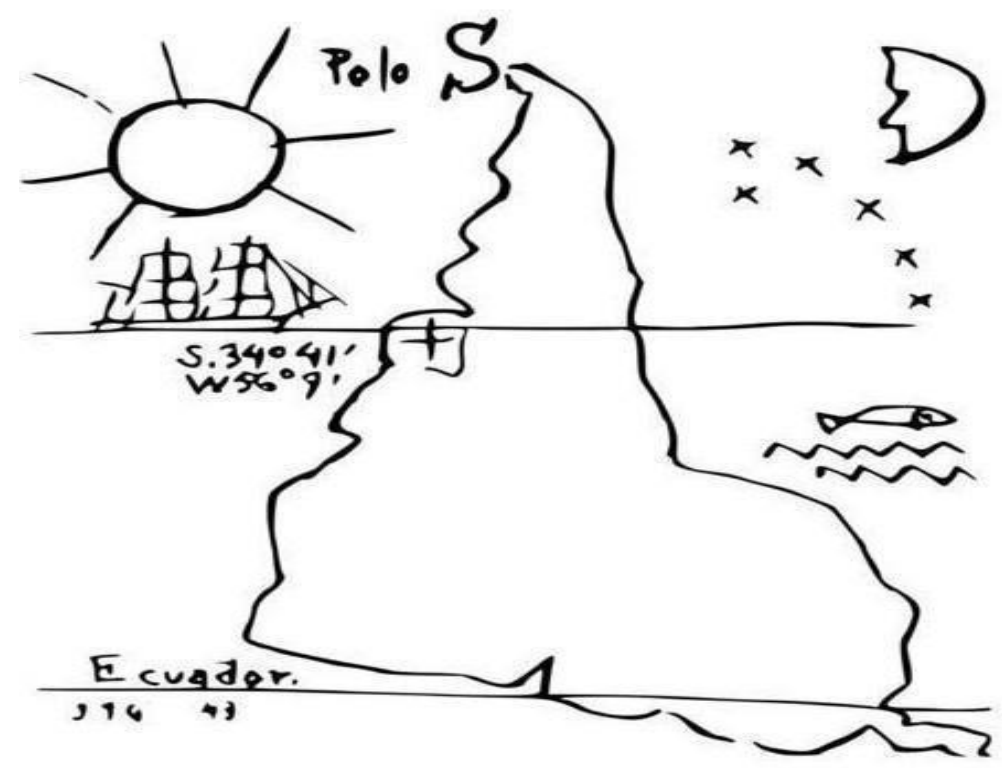

Fonte: Camisa Crítica

Nossa práxis e discussões, no percurso desses cursos, apontaram para uma vertente da

filosofia latina ou decolonial, preferindo o termo denominado por Bispo (2016) como contra colonial e etnográfico, conceito também adotado por Silvia Rivera Cusicanqui (2008), que apresenta os fundamentos por outra epistemologia: “Em El potencial epistemológico y teórico de la historia oral: de la lógica instrumental a la descolonización de la historia”. Para a cultura dos povos ameríndios, a oralidade torna-se espaço de luta e resistência. Revisando a literatura de Cusicanqui, na experiência Aymara, podemos entender que:

Lo oral indio es en Bolivia el espacio fundamental de la crítica, no sólo al ordem colonial, sino toda la concepción occidental de la historia, que sitúa lo 'histórico' tan sólo a partir de la aparición de la escritura, y legítima por lo tanto la invasión colonial como heróica misión 'civilizadora. (RIVERA CUSICANQUI, 2008).

Outros aspectos marcantes na experiência são a tradução da realidade e sua relação com o encantamento, tipo de pensamento mágico revelador de outra fase do conhecimento. No século passado, estudos como o de Lévi-Strauss (1976, p. 28), no livro Pensamento Selvagem, afirma que: "o pensamento mágico é um sistema que constitui a ciência". E, em A Identidade dos Povos do Nordeste, Carvalho (2012) discorre sobre a atitude de respeito, de valorização e 
Debates Insubmissos

de aprendizagem das cosmologias de outros grupos e povos que foram subalternizados no processo de modernização do mundo.

\section{ANÁLISE}

\subsection{Reconstruindo as narrativas audiovisuais nos territórios indígenas no contexto da} Pandemia

A premissa da construção dessa linguagem começa por olhar o mundo através da lente do celular. Passando a mais uma função, para alguns, ainda que tenham familiaridade com as constantes fotos e postagens nas mídias sociais, mas a filmagem com uma lógica de ideias sequenciadas que remetem à linguagem audiovisual de $98 \%$ do grupo, algo novo. E, este convívio de aprendizado com a mediação dos instrumentos técnicos, dos planos e de enquadres fotográficos, da produção de roteiros e edição das filmagens, desencadeou outras percepções da linguagem e das narrativas.

A imagem como principal elemento de enunciação discursiva, deixa de ser apenas as unidades de fotogramas, tornando-se e adensando a complexidade na formação do discurso, esse mediado pela edição, que gera efeitos e afeta. $\mathrm{O}$ que poderíamos denominar de conceito de montagem intelectual, desenvolvido pelo cineasta russo Sergei Eisenstein (2002), que trabalha com a premissa de que a edição fotográfica pode ser responsável pela construção de uma narrativa visual: "Este é o papel da edição: produzir significados, lógicas associativas, que podem ser explicitamente compreensíveis, ou com graus de subjetivação não tão óbvios, mas produzem um significado novo".

A nossa experiência foi permeada por desafios, dentre os quais encontram-se a instabilidade de acesso à internet, ocasionada por fatores climáticos: chuvas e ventanias, propiciando a ausência dos alunos nas aulas síncronas em até 3 dias. Estas intempéries foram disparadores também de remodelação do projeto pedagógico, com o atendimento individualizado, criando o monitoramento. $\mathrm{O}$ ensino EAD, principalmente, ao lidarmos com transposições culturais, aliado ao difícil acesso aos meios informacionais e à linguagem 


\section{Revista \\ Debates Insubmissos}

audiovisual, considerando que o ensino a distância tem um maior grau de dificuldade. Moran (2002) aponta para dois importantes fatores: o tempo e a comunicação: “o ensinar e o aprender exigem flexibilidade espaço-temporal, pessoal e de grupo, menos conteúdos de ensino e processos mais abertos de pesquisa e de comunicação" (p.28).

Outro desafio foi a adaptação pelos professores a um modelo pedagógico que priorizasse a oralidade e as experiências para construção do roteiro. Eles, entretanto, superaram tais obstáculos e conduziram a possibilidade de construir outro mundo possível, envolvendo lógicas flexibilizadas. Transpondo para construção de outra narrativa, inclusive a imposta pela edição das imagens, quando começo e fim sofrem deslocamentos, podendo territorializar, ou desterritorializar. Arma potente para fomentar lógicas inimagináveis. Poderíamos dizer que foi o "calcanhar de Aquiles" do curso. Motivando a ampliação da carga horária das oficinas, prolongando-a por mais 20 horas.

A produção audiovisual é uma encruzilhada entre a ética, a estética e a política, que encontrou no ambiente vídeo $\mathrm{O}$ Inimigo Invisível ${ }^{6}$ produzido pela professora indígena Magda Luz, que traduz orientações de higiene da OMS de como deixar sapatos fora de casa, trocar roupas e lavar os alimentos. As imagens traduzem uma geografização representativa pela escassez de água. Apontando, inclusive, para uma metodologia econômica de higienizar os alimentos. Todos os 9 vídeos guardam um elo comunal que é a autorrepresentatividade e a produção da etnomídia. Ao final do vídeo, reafirma-se a etnicidade ao enunciar o canto feito do alto de uma serra, "passarinho quando canta e alegra o mundo inteiro, e o índio quando chora é por falta do terreiro", simbolismo de alegria e de liberdade que se relaciona com a terra mãe, o lugar sagrado de dançar para os seus ancestrais.

Para Canevacci (2015), a etnomídia é uma virada epistemológica, pois cria visibilidade e representatividade indígena no espectro político brasileiro. Este fato, historicamente, remonta,

\footnotetext{
6 Vídeo produzido no Projeto Povos Indígenas em Tempo de Pandemia, através do Edital da Rede de Enfrentamento da Covid, 19, pelo DMMDC- UFBA,2020; Projeto Coordenado por Selma Capinan e Supervionado pelo PHD. Prof. Ivan Maia, sendo exibido em 12 de setembro de 2020. Disponível em: https://www.youtube.com/watch?v=tu1CPhiVRb8.
} 
ao final do regime militar quando da organização dos foros nacionais e internacionais - como o IV Tribunal Russell, em 1980, na Holanda, a articulação de visibilização de líderes indígenas, a exemplo de Mário Juruna, da etnia Xavante. Seguidamente, Raoni (Kayapó), Kopenawa (Yanomami), e a enigmática fala de Krenak, na Assembleia Nacional Constituinte, em 04 de setembro de 1987, assegurando a inclusão das garantias dos direitos indígenas. Estes fatos são um marco temporal, quanto ao início de uma visibilidade protagonista para os Povos Pindoramas.

Ensejos inspiracionais para o projeto Povos Indígenas em Tempos de Pandemia como colaborador na produção de etnomídia.

Etnomídia é comunicar expressando sua identidade étnica para que exista um real empoderamento na apropriação das novas tecnologias pelos povos e culturas que a usam como ferramenta, fugindo da colonização audiovisual ou midiática dos formatos de mídia padronizados pelo pensamento ocidental, apresenta uma natureza contra hegemônica (TUPINAMBÁ, 2020, s/p).

O vídeo cuja temática é A Prevenção ${ }^{7}$, produzido pelo professor indígena Jadson Ewerton, um jovem iniciado nos encantos, cuja tradição familiar vem sendo trazida pela sua avó, uma zeladora de Praiá $^{8}$, significa dizer que nasce embalado pelo ritmo do Toré, sendo a tradição algo, portanto, visceral. Ainda que o tema proposto por ele tenha sido a prevenção, o vídeo também fala sobre o preconceito. Em todo o processo de construção, o que mais lhe chamava a atenção era o cuidado, mas a sua transposição é visivelmente perpassada pelo discurso da falta dos rituais, pela suspensão das atividades devocionais.

O vídeo se inicia com um Background (BG) de um toante ${ }^{9}$ e, nas entrelinhas, a preparação para participar das rodas, mediante o fumo do Campió ${ }^{10}$, como sinal de limpar as

\footnotetext{
${ }^{7}$ Vídeo produzido no Projeto Povos Indígenas em Tempo de Pandemia, sendo exibido em 12 de setembro de 2020. Disponível em: https://www.youtube.com/watch?v=2ik281dedBM

${ }^{8}$ Aquele que guarda os cuidados de cada um dos encantados, nas suas especificidades. Praiá são pessoas iniciadas nos encantos e que nos trabalhos utilizam vestimentas com cores e ornamentos de acordo o encantado.

${ }^{9}$ Toante são os cantos sagrados que evocam forças e permitem o transe.

${ }^{10}$ Cachimbo em forma cônica fumado nos rituais e incorporado no cotidiano.
} 
emoções, o pensamento, para viver outras realidades, no toré, ou na vida cotidiana. Então, a narrativa do vídeo trata das faltas e da relação com as práticas ancestrais.

Todos os vídeos produzidos pelo Projeto serviram para reafirmar as suas identidades. Dos 9 curtas metragens produzidos, apenas 2 não utilizaram cantos sagrados ou as tradições do cotidiano. As narrativas inserem o cotidiano e é deste lugar específico, concreto e familiar, que se faz a difusão das ideias, que unem ciência, tradição e criatividade.

A geografização do audiovisual e o ciberespaço possibilitam mover-se por diferentes espaços, ainda que sem sair da Aldeia. Protagonizando a sua própria narrativa entre a ficção e o real, entre o documentário e a poesia, o lirismo imbuído de autoapresentação do falar ao sentir.

As sociedades de periferia têm estado sempre abertas às influências culturais ocidentais, e agora, mais do que nunca. A ideia de que esses são lugares fechados etnicamente puros, culturalmente tradicionais e intocados até ontem pelas rupturas da modernidade - é uma fantasia ocidental sobre a alteridade: uma fantasia colonial sobre a periferia, mantida pelo Ocidente, que tende a gostar de seus nativos apenas como puros e de seus lugares exóticos apenas como intocados (HALL, 2002, p. 79-80)

Espero que os leitores possam assistir a todos os vídeos cujos links serão colocados ao longo de algumas análises e os outros, ao final do artigo. Não irei comentar, nem analisar todos eles, mas o aspecto de centralidade dentre eles foi a etnicidade audiovisual.

Mãe de Deus ${ }^{11}$ é um vídeo produzido por Bárbara Oliveira, cuja temática se refere a um canto sagrado que fala das sementes derramadas. São estas sementes do maracá que representam o próprio cosmo, o instrumento de conexão entre os dois mundos - terrestre e espiritual - e que também formam os seres humanos nas cosmologias de alguns povos. O toante anuncia a importância dos Seres criados a reverenciarem o poder da Mãe de Deus, por Ser "poderosa", de luz e que protege os seus filhos. Assim, o canto espraia-se pelas montanhas, reino do castelo dos Encantados. Na cosmogonia Pankararu, assim como para os Yanomami,

\footnotetext{
11 Vídeo produzido no Projeto Povos Indígenas Pankararu, do Edital da Rede de Enfrentamento ao Covid 19DMMDC-2020, exibido em 12 de setembro, com a Coordenação Selma Capinan. Disponível em: https://www.youtube.com/watch?v=hp2JlFYLhZ4
} 


\section{Revista \\ Debates Insubmissos}

de acordo Kopenawa (2019, p. 121), “os espíritos que vivem nelas são muito mais numerosos do que humanos".

Mãe de Deus é um toante que fala sobre o poder feminino, da Mãe de Deus e da mãe Natureza, que se fundem. $\mathrm{O}$ vídeo retrata o engajamento entre a ancestralidade feminina, tendo como porta-voz encarnada a liderança das mulheres Pankararus, Bárbara Oliveira, reconhecida na Aldeia como Bárbara Pankararu, cujo lugar de origem é o próprio sobrenome. Uso comum entre os povos originários: o nome de família é estendido ao da própria etnia. Líder Feminina que desenvolve trabalhos de apoio às mulheres e também uma gestora de escola indígena.

A primeira cena fala muito sobre a espiritualidade de Bárbara. Aquela abelha na flor, no primeiro fotograma não é apenas uma relação estética, mas fala sobre um encantado. Nessa cosmovisão, a divindade se apresenta pela natureza. Percebem-se, então, as sobreposições de culturas e de religiões quando se pede à Mãe, como "o rogai por nós" traz à tona o tom dos cânticos católicos. É um vídeo entrecortado de vozes femininas. A ancestral Oliveira, que vê a máscara como uma "mochilinha de cabrito", nostalgicamente faz um canto de trabalho, na casa de farinha. O vídeo deixa a mensagem de que entre o céu e a terra existe um cuidar um do outro, mas especialmente, da importância de preservar o "tronco velho". As imagens finais, em fusão mulher natureza, unificam as existências.

Nos dois vídeos, cuja temática trata das questões do afeto ou das questões psicossociais, um se volta para a relação da criança com os pais. Especialmente, no vídeo, a mãe protagoniza e assume o compromisso da educação do filho. Ele expressa a nostalgia traduzida pelas imagens, correlatas ao sentimento inóspito de tristeza, em preto e branco, cujos limites da criança atrás das grades, contrapõem-se à liberdade indígena e associam a saudade de frequentar a escola e encontrar os amigos. Fazendo, assim, emergir o olhar da pandemia sob o ponto de vista da criança. Para teóricos como Ponte (2018), as crianças são sujeitos ativos na construção da realidade social. A construção do vídeo traz uma linguagem atualizada desde a trilha sonora à estética.

Entretanto, a forma de brincar e de criar o carrinho de papelão traduz o lugar e a singeleza. Este vídeo, ao ser postado no YouTube, teve problemas quanto à trilha escolhida, 
algo que já havíamos tratado em um dos componentes do curso sobre direitos de imagens e sobre os direitos autorais, entretanto só a experiência trouxe a compreensão real do significado da autoria. Este foi o único vídeo em que a trilha não era composta dos toantes, ou das canções da tradição Pankararu. Sidiclea, diretora e roteirista, é agente de saúde, produziu o vídeo denominado Um outro olhar ${ }^{12}$.

Esse vídeo apresenta a problemática da educação considerando a transição para o ensino remoto. A educação passa pelas rimas de um cordel, mas mostra a luta e a resistência da educação indígena. Discurso embalado também pela tradição, (e): um vídeo entremeado de poesia. Joelma faz parte de um grupo de poetas, poetisas e amantes das letras, em Pankararu. Ela é uma educadora indígena. O cotidiano da luta está marcado pelo toante "lá vem o sol, lá vem a Lua". Este ciclo natural é também ordenador do planejamento dos professores, no preparo das aulas, que tratam dos ciclos das principais tradições, de dezembro a março, e também da agricultura. Lembrando que a escola indígena é um direito garantido constitucionalmente normatizado pela resolução n 3/993 do CNE/CEB, de 10 de novembro de 1999, que fixou as Diretrizes Nacionais para o Funcionamento das Escolas Indígenas e diferencia o seu calendário, metodologia e conteúdos, servido como um demarcador indenitário. E assumido dentre todos os povos, como espaço de resistência e luta.

O preconceito foi o tema tratado por Ana Neide, no vídeo cujo título é PreconceitoCovid $19^{13}$. Ela é também professora do Povo Pankararu. O vídeo inicia com o depoimento de uma das primeiras pessoas infectadas da Aldeia Espinheira, região das entre Serras. Naturalmente, este agrupamento sofre uma rivalidade e nas "brincadeiras", entre o próprio povo, há um tom entre palavras e silêncio carregado de sentido. A origem deste sentimento entre eles, eu ainda não sei.

\footnotetext{
12 Vídeo produzido no Projeto Povos Indígenas Pankararu, do Edital da Rede de Enfrentamento ao Covid 19DMMDC-2020. Coordenação Selma Capinan. Disponível em: https://www.youtube.com/watch?v=olEw-yeVJ80

${ }^{13}$ Vídeo produzido no Projeto Povos Indígenas em Tempo de Pandemia, pelo Edital do DMMDC-UFBA, 2020. Disponível em: https://www.youtube.com/watch?v=aGH1cvVNUdM
} 


\section{Revista \\ Debates Insubmissos}

O vídeo também aponta a precariedade a que estão expostos pela falta de teste que comprove o fim da carga viral e a impossibilidade financeira de o paciente pagar para refazer o teste, após o tratamento. A pontuação sobre o preconceito é feita pela compreensão das crianças. Uma bela lição. Sendo o fio condutor desta narrativa trazido pelo anúncio do canto de pássaros e pela fé nos encantados. Um chamado para a humanização nas relações em tempo de pandemia. Uma denúncia, mas também um chamado para os acordes da amizade e do coração. E, mais uma vez, as sementes do maracá chamando o mundo espiritual. Assim, o tema central do vídeo da Ana Neide apenas mostra a "ponta do iceberg” da precarização da saúde indígena.

\section{CONCLUSÕES}

O Projeto Povos Indígenas em Tempos de Pandemia além de cumprir uma ação de intervenção preventiva difundindo conhecimentos científicos, de práticas adequadas aos cuidados pessoais com vista à profilaxia, produziu afetos, encontros e promoveu a visibilidade interna e externa do Povo Pankararu, chamando a atenção internacional. E, mediante contatos de Márcia Kambeba, obtivemos doações, advindas da Alemanha, com doações que puderam melhorar as condições em relação a equipamentos para a saúde dos Pankararus aldeados, já que possibilitou a compra de termômetros, tensiômetros, oxímetros, máscaras, equipamentos para medir a glicose, dentre outros, o que contribui para minimizar os problemas existentes, bem como uma melhor assistência aos indígenas dessa localidade.

Vale ressaltar que de março a junho de 2020, de acordo com os informes da Coordenação de Saúde Indigena do Polo Pankararu (Consei), haviam sido disponibilizados 100 testes rápidos, o que revelou a insustentabilidade da saúde pública. Significando que a pandemia do Coronavírus reafirma espaços opacos ${ }^{14}$, evidenciando as contradições de classe, raça, gênero, assim como o atual estado de assistência à saúde indígena. À medida que os direitos são aviltados, o exercício da cidadania está ameaçado. E, nesse tempo de pandemia, no Território Pankararu, na aldeia Bem Querer de Baixo, a mais nova área de retomada, cogitou-

\footnotetext{
${ }^{14}$ Termo utilizado por Milton Santos para se referir aos espaços de falta, sem circulação de tecnologia e dinheiro
} 
se criar uma área de isolamento para as pessoas contaminadas, no espaço onde funcionava um posto médico até o ano de 2018, quando esta área estava ainda na posse dos grileiros. O posto foi fechado desde a desentrusão e encontra-se como um espaço ocioso pela falta de recursos.

O plano de uma área para tratamento da Covid-19 não logrou êxito, efetivamente, por não contar com os poderes públicos para as adaptações e compra de materiais. Nos postos de saúde, faltava a infraestrutura necessária para atender a esta especificidade pandêmica. Estes aspectos nos remetem, portanto, aos desafios referentes à implementação da atenção à saúde diferenciada dos povos indígenas, incluindo também as práticas importantes das ervas, das rezas que fazem parte da tradição, ao tratamento da saúde dos povos tradicionais.

Até meados de outubro de 2020, menos de 0,5\% da população Pankararu, nas 17 aldeias, haviam sido testados. Neste mesmo período, 26 casos foram confirmados, sem que as mortes existentes apontassem para a contaminação pelo Covid-19. Na primeira semana de outubro, as restrições foram flexibilizadas e as atividades nos terreiros, onde ocorrem as práticas religiosas tradicionais, foram retomadas. Entretanto, o CONSEI não tinha recebido testes suficientes para balizar a tomada de decisão pela coletividade. De março até junho, só chegaram 160 testes.

A expressão Bem Viver embora tenha surgido no contexto das experiências indígenas andinas, já extrapola seu âmbito de origem, como adverte o autor, a exemplo do que acontece com a expressão Ubuntu, noção africana que traduz uma filosofia fundada no princípio de que "Eu sou porque somos". Reconhece como paisagem, ou seja, como ponto de encontro para atos humanos e não humanos, como um arquivo de atividades humanas e não humanas, portanto, estes conceitos entrelaçados nos alertam para que possamos desenvolver padrões sociais mais equânimes, formando um ecossistema (humanos e não humanos), em equilíbrio. Este entendimento foi aprofundado ao longo da nossa jornada junto ao Povo Pankararu, durante o curso, retroalimentando os princípios fundantes do curso.

Um dos aspectos relevantes foi o desdobramento do curso o qual criou um coletivo de memória e ancestralidade denominado Y-MB-U, que em tupi, significa árvore que dá água. $\mathrm{O}$ Imbuzeiro, ou também denominado Umbuzeiro, pode reservar até uma tonelada de água nas raízes, fazendo com que se possa sobreviver toda época de seca, além de ser uma árvore sagrada 


\section{Revista \\ Debates Insubmissos}

para o Povo Pankararu. Resistência transposta ao ambiente virtual, gerando um ambiente de visibilidade e de ampliação da luta pelos seus direitos.

Apesar da vivência com o Povo Pankararu e minha estada por longos períodos nas Terras Sagradas, muitos aspectos continuam sendo desvendados e novos aprendizados se fazem a cada encontro. Portanto, a troca de experiência, ainda que virtual, tornou-se uma aventura para todos nós participantes do projeto.

Outro grande desafio foi a falta de reuniões do grupo de professores, já que estas basicamente não ocorreram. Ouvimos muito pouco uns aos outros, no coletivo. As comunicações acabaram sendo individualizadas, em decorrência da dificuldade de conciliar os calendários e os horários dos professores participantes. Apesar deste contraponto, o resultado demonstrou o nível de comprometimento de toda equipe. A responsabilidade, a qualidade na execução e a empatia com os alunos nos levaram à superação dessa dinâmica das rodas pedagógicas, entre professores.

A ampliação da carga horária para 200 horas, com a introdução do monitoramento individualizado demonstrou a visão política de educação para a cidadania, e de um planejamento flexível e produzido conjuntamente. Fortalecendo aspectos transdisciplinares e interculturais.

E, ao findar da nossa jornada extensionista, percebemos que os conhecimentos produzidos extrapolaram o uso dos recursos audiovisuais, para a prevenção, mas a própria experiência de um curso remoto foi transposta, posteriormente, para as práticas educativas pelos professores, como o uso do Google Class, edição de material didático para os alunos. Portanto, impactos que resultaram em outras práticas educacionais.

O material produzido tornou-se um veículo de difusão do conhecimento, mesmo dentro da própria comunidade, por meio das práticas pedagógicas, na retomada das aulas em 2021, e a criação do Coletivo Y0Mb-U, gerou a criação do Museu Virtual do Povo Pankararu, cujo 
link ${ }^{15}$ encontra-se também em nota de rodapé, demonstrando a relevância do projeto de Extensão Povos Indígenas em Tempo de Pandemia.

\section{REFERÊNCIAS}

APIB- Articulação dos Povos Indígenas do Brasil. Relatório de Junho 2020. Disponível em: http://apib.info/files/2020/06/Plano-Indi\%CC\%81gena-de-Enfrentamento-ao-Covid-19Versa\%CC\%83o-final.docx.pdf. Acesso em: 10 jun 2020.

BAUMAN, Zygmunt. Medo líquido. Rio de Janeiro: Jorge Zahar Editor, 2008. 229 p.

CANEVACCI, Massimo. Autorrepresentação: movimentar epistemologias no contexto da cultura digital e da metrópole comunicacional. Revista Novos Olhares, v. 4, n.1, p. 16-20, 2015. Disponível em: http://www.revistas.usp.br/novosolhares/article/view/102237. Acesso em: 28 abr. 2020.

CARDOSO, Thiago Mota. A arte de viver no Antropoceno: um olhar etnográfico sobre cogumelos e capitalismo na obra de Anna Tsing. Revista ima.com, ano 6 - N 14 "Fabulações Miceliais" ISSN 2359-4705. Disponível em: http://climacom.mudancasclimaticas.net.br/a-arte-de-viver-no-antropoceno-um-olharetnografico-sobre-cogumelos-e-capitalismo-na-o. Acesso em: 20 sep 2020.

CUSICANQUI, Silvia Rivera. Ch'ixinakax utxiwa. Una reflexión sobre prácticas y discursos descolonizadores. Buenos Aires: Tinta Limón, 2010. Pinturas. 80 pp.

DE CARVAlHO, M. R. G. A Identidade dos Povos do Nordeste. Anuário Antropológico, v. 7, n. 1, p. 169-188, 19 jan. 2018. Disponível em: https://periódicos.unb.br/index.php/anuarioantropologico/article/view/6242. Acesso em 12 set 2020.

DELEUZE, Gilles. Conversações (1972-1990). São Paulo: Editora 34, 1992.

EISENSTEIN, Sergei. A forma do filme. Rio de Janeiro: Jorge Zahar, 2002.

EISENSTEIN, Sergei. O sentido do filme. Rio de Janeiro: Jorge Zahar, 2002.

FERRAÇO, Carlos; ALVES, Nilda. Conversas em redes e pesquisas com os cotidianos: a força das multiplicidades, acasos, encontros, experiências e amizades. In: RIBEIRO, Tiago et al. Conversa como metodologia de pesquisa: por que não? Rio de Janeiro: Ayvu, 2018.

FOUCAULT, Michel. História da sexualidade, 2: o uso dos prazeres. Rio de Janeiro: Edições Graal, 1984.

HALL, Stuart. A identidade cultural na pós-modernidade. Rio de Janeiro-RJ: 2002.

\footnotetext{
${ }^{15}$ Link do Museu Virtual do Povo Pankararu https://www.museudopovopankararu.com.br/.
} 
HEIDEGGER, Martin. Conferências e escritos filosóficos. São Paulo: Abril Cultural, 1979.

HYMES, D. On Communicative Competence. In: PRIDE, J. B. e HOLMES, J.

Sociolinguistics. England: Penguin Books, 1972. 381 p. p.269-293.

IBGE, Instituto Brasileiro de Geografia e Estatística. Características étnico-raciais da População: Classificações e Identidades. Rio de Janeiro, 2013. Disponível em: https: biblioteca.igbe.gov.br. visualização; livros; liv63405.pdf. Acesso em: 5 agos de 2020.

KRENAK, Ailton. Ideias para adiar o fim do mundo. São Paulo: Companhia das Letras, 2019.

KOPENAWA, Davi; BRUCE, Albert. A queda do céu: palavras de um xamã yanomami. 7a Edição, São Paulo, Companhia das Letras, 2010.

LEFF, Enrique. A aposta pela vida: imaginação sociológica e imaginários sociais nos territórios ambientais do Sul. Petrópolis, RJ: Vozes, 2016.

LEVI-STRUSS, C.O. O Pensamento Selvagem. Costa Maria Celeste e Almir de Oliveira Aguiar( trad). São Paulo. Companhia das Letras, 1976.

MATURANA, Humberto. Emoções e linguagem na educação e na política. $4^{a}$ reimpressão. Belo Horizonte: Editora UFMG, 2005.

MBEMBE, A. Necropolítica. In: Arte \& Ensaios. Revista do PPGAV/EBA/UFRJ. n. 32, 2016.

MORAN, Edgar, Os Sete Saberes Necessários à Educação do Futuro. 2. ed. - São Paulo : Cortez ; Brasília, DF : UNESCO, 2000.

NÓVOA, Antonio (Org.). Os professores e a sua formação. 3. ed. Lisboa: Publicações Dom Quixote, 1997.

PONTE, Vanessa Paula da. Beleza, produção e normalização do corpo em narrativas de crianças. Civitas, Rev. Ciênc. Soc, Porto Alegre, v. 18, n. 1, p.153-170, Apr.2018. Disponível em: hhttp://www.scielo.br/scielo.php?script=sci_arttext\&pid=S151960892018000100153\&lng=en\&nrm=iso>. Acesso em: 11 out. 2020.

SANTOS, Milton. Espaço do Cidadão. 7ª . Ed. São Paulo: Editora da USP, 2007.

SERRES, Michel. Tempo de crise: o que a crise financeira trouxe à tona e como reinventar nossa vida e o futuro. Rio de Janeiro: Bertrand Brasil, 2009.

SILVA, BISPO. Colonização, quilombos, modos e significações: Colonization, quilombos, modes and meanings. Revista Argumentos, v. 15, n. 2, p. 250-258, 23 nov. 2018.

STENGERS, Isabelle. No tempo das catástrofes: resistir à barbárie que se aproxima. São Paulo: Cosac Naify, 2015.

TORRES, C. La Escuela del Sul. Arte Mercosul. 1997. Disponível em: http www.art mercosur.org.uyartistastorressur.html. Acesso em: 16 mai 20, 
TSING, Anna Lowenhaupt. Viver nas ruínas: Paisagens multiespécies no antropoceno. Brasília: IEB, Mil Folhas, 2019.

TUPINAMBÁ, Renata. Iniciação científica - Questionário. Mensagem recebida por em 13 abr 2018. In: RIBEIRO, Lucas Fernando RIBEIRO e Mônica Panis KASEKER, 41 Congresso Brasileiro de Ciência da Comunicação- Joinvile - SC- 2a 8;09;2018. Disponível em: https://portalintercom.org.br;nacional;R13-1554-1pdf.

Recebido: $15 / 10 / 2020$

Aprovado: 20/09/2021 